\title{
Short communication: The effects of experimentally induced Escherichia coli clinical mastitis on lying behavior of dairy cows
}

\author{
J. A. Cyples, ${ }^{\star}$ C. E. Fitzpatrick,† K. E. Leslie,† T. J. DeVries,‡ D. B. Haley,† and N. Chapinal† ${ }^{1}$ \\ *Department of Animal and Poultry Science, University of Guelph, ON, Canada N1G 2W1 \\ †Department of Population Medicine, University of Guelph, ON, Canada N1G 2W1 \\ ‡Department of Animal and Poultry Science, University of Guelph, Kemptville Campus, ON, Canada K0G 1J0 \\ §Animal Welfare Program, University of British Columbia, BC, Canada V6T 1 Z4
}

\section{ABSTRACT}

Clinical mastitis is a commonly occurring and economically important problem in the dairy industry. Researchers have suggested that changes in lying behavior could be useful as early indicators of cow discomfort and poor welfare. The objective of this study was to determine the associations between the onset of illness resulting from experimentally induced clinical mastitis and measures of lying behavior. Clinical mastitis was induced in 21 lactating dairy cows (parity $=2.0 \pm 1.0$, range $=1$ to 4 ; days in milk $=61 \pm 18$ ) by intramammary infusion of 25 or $100 \mu \mathrm{g}$ of Escherichia coli lipopolysaccharide (LPS) into 1 uninfected mammary quarter. Lying behavior was monitored from $2 \mathrm{~d}$ before through $3 \mathrm{~d}$ after the LPS challenge by fitting each cow with a data logger. Calculated outcome measures were total lying time, lying time on the side of the intramammary infusion, number of lying bouts, and average lying bout duration. Cows spent less time lying down on the day of the challenge compared with the $2 \mathrm{~d}$ before (633.3 vs. $707.0 \mathrm{~min} / \mathrm{d} ; \mathrm{SE}=29.6)$, particularly during the 4 to $7 \mathrm{~h}$ following LPS infusion. However, no significant relationship was found between the mammary quarter challenged and cow preference for lying side throughout the episode of induced clinical mastitis. Given that lying is a high-priority behavior in dairy cows and that increased lying time is an adaptive sickness behavior to facilitate recovery, we infer that this reduction in lying time may present a concern for cows with clinical mastitis. Although additional studies with larger numbers of animals are needed, automated monitoring of lying behavior could be an important component of the on-farm early detection of health problems, such as mastitis, in the future.

Key words: activity, coliform mastitis, sickness behavior, pain

Received November 10, 2011.

Accepted January 9, 2012.

${ }^{1}$ Corresponding author: nchapinal@yahoo.com

\section{Short Communication}

In dairy cattle, lying down is a high-priority behavior, which ensures that the necessary time to rest and ruminate is achieved (Munksgaard et al., 2005). On average, a typical dairy cow spends approximately 11 h/d lying down (Ito et al., 2009). Limiting the amount of time that can be designated to lying is considered detrimental to a cow's welfare (Metz, 1985; Munksgaard and Simonsen, 1996). The deprivation of lying time has also been linked to physiological changes in the hypothalamic-pituitary-adrenal axis (Ruckebusch, 1974; Munksgaard and Simonsen, 1996) and is thought to be related to a state of chronic stress (Ladewig and Smidt, 1989). Having adequate opportunity to exhibit this behavior has been linked to optimal production levels and welfare in dairy cattle (Haley et al., 2000; Fregonesi and Leaver, 2001).

Physical discomfort may alter lying patterns and potentially affect the side on which a cow will decide to rest. Grant et al. (1990) reported that dairy cattle fitted with a rumen cannula on their left side spent less time lying on their left side compared with noncannulated control cows; these researchers suggested this was due to discomfort caused by the cannula. This same phenomenon has been observed in pregnant cows later in gestation that spent more time lying on their left side probably because of discomfort when lying on the right side as the fetus enlarges into the right abdominal cavity (Arave and Walters, 1980; Forsberg et al., 2008). On the other hand, sickness causes lethargy and depression and, therefore, decreased activity and increased sleep and lying time, as an adaptive response to facilitate recovery (Hart, 1988; Johnson, 2002). However, some recent evidence suggests that cows with mastitis stand for longer, likely because of the discomfort caused by the sore udder when lying. Zimov et al. (2011) induced mastitis in 10 cows by intramammary infusion of Escherichia coli LPS in 1 quarter and found that they spent less time lying in the first $12 \mathrm{~h}$ after LPS infusion compared with 12 to $24 \mathrm{~h}$ after infusion. However, those authors did not record baseline lying 
behavior before the mastitis challenge. Similarly, Siivonen et al. (2011) experimentally induced mastitis in 6 cows and found that cows spent less time lying down in the hours following LPS infusion than on the day before. Contrary to their hypothesis, they did not find that the proportion of time spent lying on the side of the affected quarter decreased after mastitis induction. More research, with a larger sample of animals continuously monitored before and after mastitis induction, is thus needed.

The objective of this study was to determine the associations between the onset of illness resulting from experimentally induced clinical mastitis and measures of lying behavior. We hypothesized that cows would spend less time lying down during an episode of induced mastitis compared with the days before induction, and that they would spend a lesser proportion of time lying on the side of the affected quarter.

Twenty-one Holstein dairy cows (mean $\pm \mathrm{SD}$; parity $=2.0 \pm 1.0$, range $=1$ to $4 ; \mathrm{DIM}=60.6 \pm 18.5)$ were enrolled in groups $(\mathrm{n}=7)$ of 3 cows at a time, from July 2010 to March 2011. Only animals with no clinical signs of illness and no history of treatment for illness for the last $30 \mathrm{~d}$ were selected. All animals were housed in the tie-stall facility at the Ponsonby Dairy Research Centre of the University of Guelph (Ontario, Canada). Cows were fed a TMR 3 times daily at approximately 0900, 1300, and $1500 \mathrm{~h}$, and were milked twice daily at approximately 0530 and $1600 \mathrm{~h}$. The experiment was approved by the University of Guelph Animal Care Committee before the study commenced, and all work with animals was done according to the guidelines set by the Canadian Council on Animal Care (2009).

Each cow enrolled in the study was challenged with an intramammary infusion of purified bacterial E. coli LPS (from Escherichia coli 0111:B4; Sigma-Aldrich Co., St. Louis, MO) in 1 hind quarter. Only quarters that had an SCC of $<200,000$ cells/mL (DeLaval Direct Cell Counter, DeLaval International AB, Tumba, Sweden) $3 \mathrm{~d}$ before the challenge were selected. Preference was given to the right hind quarter if it met the eligibility criteria. If not, the left hind quarter was evaluated and challenged $(\mathrm{n}=5)$. Prior to infusion, teats to be infused with LPS were dipped with an iodine-based disinfectant and further cleaned with cotton swabs soaked in $70 \%$ ethanol. Following the morning milking (0700 $\mathrm{h}$ ) on the challenge day (d 0 ), cows were infused with purified LPS, which was reconstituted in $10 \mathrm{~mL}$ of sterile saline solution. The infusion was performed in the previously selected quarter using a $12-\mathrm{mL}$ syringe fitted with a sterile teat cannula (Jorgensen Laboratories Inc., Loveland, CO). The majority of the study animals received $25 \mu \mathrm{g}$ of purified LPS $(\mathrm{n}=18)$, whereas the remainder of the animals received $100 \mu \mathrm{g}$ of LPS ( $\mathrm{n}=$
$3)$. Teats were dipped with an iodine-based teat disinfectant immediately following infusion. The remaining 3 quarters of each cow were not challenged. The LPS infusion resulted in a consistent, moderate to severe case of clinical mastitis of limited duration $(<24 \mathrm{~h})$, regardless of the LPS dosage.

Lying behavior was monitored with data loggers (Hobo Pendant G Data Logger, Onset Computer Corp., Pocasset, MA), as validated by Ledgerwood et al. (2010), attached to the lateral aspect of the right metatarsus of each cow using a flexible bandage (CoFlex, Andover Coated Products Inc., Salisbury, MA). The loggers were programmed to record the tilt of the leg in 3 axes at 1-min intervals. This information was used to determine whether the cow was standing or lying, and the side she was lying on, and subsequently calculate total lying time, lying time on the side of intramammary infusion, number of lying bouts, and duration of lying bouts. These data were recorded from $2 \mathrm{~d}$ before LPS infusion ( $\mathrm{d}-2$ and $\mathrm{d}-1)$ through $3 \mathrm{~d}$ after LPS infusion (d 0, d 1, and d 2). Due to technical problems, data from 2 of the animals were discarded.

Statistical analyses were performed with SAS (version 9.2, 2003; SAS Institute Inc., Cary, NC) considering the cow as the experimental unit. Lying behavior data were summarized by cow and day to obtain daily total lying time, lying time on the side of intramammary infusion, number of lying bouts, and average lying bout duration. The proportion of total lying time per day that each cow spent lying on the side of the infused quarter was calculated. Experimental days were adjusted to start at $0700 \mathrm{~h}$, time when cows were infused with LPS. An exploratory analysis showed no differences between data from $\mathrm{d}-2$ and $\mathrm{d}-1$; therefore, data were averaged to obtain 1 baseline value per cow for each lying behavior variable. Data were analyzed using mixed models (PROC MIXED), considering day as a repeated measure over cow, enrollment group as a random effect, parity (primiparous or multiparous), DIM at infusion, and infusion side (left or right hind quarter) as fixed effects, and biologically plausible 2-way interactions. The covariance structure selected was unstructured, compound symmetry, or Toeplitz, based on the lowest Akaike's information criterion. Variables and interactions were removed from the final model if $P>0.05$ by manual backward selection. Dunnett's 2-tailed test was used as a post hoc test to evaluate differences between baseline and subsequent days. Residuals were examined after each model to verify normality and homogeneity of variances, and to detect possible outliers and influential points.

Lying time was also summarized by cow, day, and hour to assess diurnal patterns. An exploratory analysis showed that diurnal patterns prechallenge $(\mathrm{d}-2$ and $\mathrm{d}$ 
Table 1. Least squares means and standard error for lying behavior variables for 19 Holstein dairy cows before (baseline) and after (d 0 to d 2) the infusion of a hind quarter with Escherichia coli LPS

\begin{tabular}{|c|c|c|c|c|c|}
\hline \multirow[b]{2}{*}{ Variable } & \multicolumn{4}{|c|}{ Time period relative to infusion ${ }^{1}$} & \multirow[b]{2}{*}{$\mathrm{SE}$} \\
\hline & Baseline & d 0 & d 1 & d 2 & \\
\hline Lying time on infusion side $(\mathrm{min} / \mathrm{d})$ & 327.8 & 289.5 & 318.9 & 332.4 & 30.8 \\
\hline Proportion of time lying on infusion side ${ }^{2}$ & 0.51 & 0.48 & 0.46 & 0.48 & 0.03 \\
\hline Lying bouts (no./d) & 11.4 & 10.4 & 12.7 & 11.8 & 1.0 \\
\hline Lying duration (min/bout) & 54.9 & 56.1 & 55.6 & 57.5 & 5.1 \\
\hline
\end{tabular}

${ }^{1}$ Baseline was the average of $2 \mathrm{~d}$ before infusion. Experimental days were adjusted to start at $0700 \mathrm{~h}$ (time of infusion).

${ }^{2}$ Controlling for infusion side.

$* P=0.005$ compared with baseline (Dunnett's 2-tailed test).

-1 ) and postchallenge (d 1 and d 2) were very similar, and therefore data from those $4 \mathrm{~d}$ were averaged to create 1 baseline value per hour. The baseline diurnal pattern was compared with the diurnal pattern on the day of the challenge by using a mixed model that included time period (baseline or day of challenge) and hour as repeated measures over cow, enrollment group as a random effect, parity and DIM as fixed effects, and biologically plausible 2-way interactions. A Toeplitz covariance structure was selected based on the lowest Akaike's information criterion. Variables and interactions were removed from the final model if $P>0.05$ by manual backward selection. Residuals were examined after each model to verify normality and homogeneity of variances, as well as to detect possible outliers and influential points.

Cows spent less total time lying down on the day of challenge compared with baseline measures (10.6 vs.
$11.8 \mathrm{~h} / \mathrm{d} ; \mathrm{SE}=0.5 ; P=0.005 ;$ Table 1$).$ No differences were seen concerning the number of lying bouts, the average duration of the lying bouts, or the side on which the cow lay (control vs. challenged quarter) between the baseline and any of the subsequent days. Parity and DIM had no effect on any of the outcome variables.

When the diurnal patterns were assessed, we observed an interaction between period (baseline as an average of $2 \mathrm{~d}$ before and $2 \mathrm{~d}$ after challenge, or day of challenge) and hour of the day $(P<0.001 ;$ Figure 1$)$. The diurnal pattern of lying behavior on the day of challenge showed a deviation from the baseline diurnal pattern, particularly during the 4 to $7 \mathrm{~h}$ following infusion.

The results of the current experiment indicate that reductions in total lying time occurred during an episode of experimentally induced $E$. coli clinical mastitis. However, mastitis did not affect the number of lying bouts, the average bout duration, or the proportion of

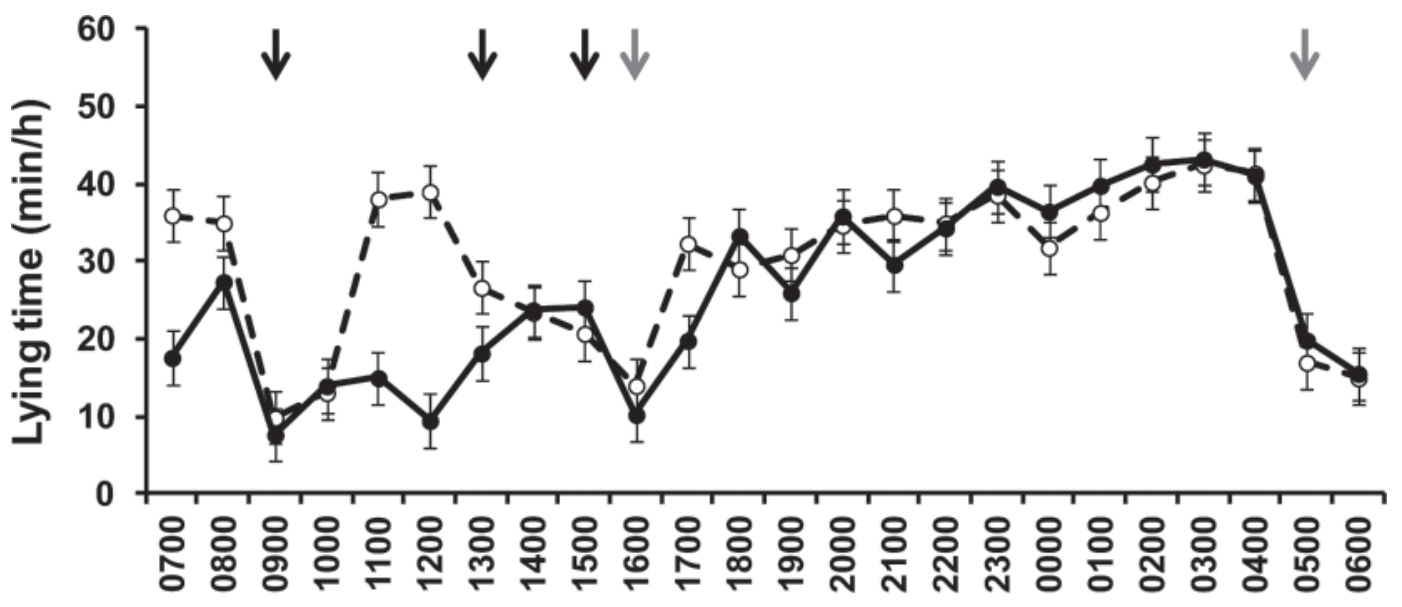

Time of day

Figure 1. Least squares means $( \pm \mathrm{SE}$; $\mathrm{min} / \mathrm{h})$ of time that Holstein dairy cows $(\mathrm{n}=19)$ spent lying down the day they were infused with Escherichia coli LPS in a hind quarter (solid line), compared with the $2 \mathrm{~d}$ before and $2 \mathrm{~d}$ after infusion (dashed line). Experimental days were adjusted to start at $0700 \mathrm{~h}$ (time of infusion). Cows were fed at approximately 0900, 1300, and $1500 \mathrm{~h}$ (black arrows) and milked at approximately 0530 and $1600 \mathrm{~h}$ (gray arrows). 
time spent lying on the side of the affected quarter. The decrease in lying behavior is in contrast to the typical decrease in activity described in sick animals (Hart, 1988; Dantzer, 2001; Johnson, 2002). Sickness behavior (e.g., immobility, sleepiness) is a coping mechanism that enables the individual to better counteract infection, thereby facilitating recovery (Aubert, 1999). However, sickness behavior may be interrupted by other stimuli that are evaluated as more relevant to the priorities of the animal, such as fear or pain. In the case of the current study, the mastitis-induced cows likely tried to cope with the discomfort and pain caused by the swollen udder by standing, thereby compromising their need to lie down. It may be possible that lying, through direct contact with a hard surface (stall floor), causes more pain to the udder than having the udder hang freely while standing.

In agreement with our results, Siivonen et al. (2011) reported that cows spent less time lying down in the 20 $\mathrm{h}$ following mastitis induction with LPS, when the most acute signs of mastitis (e.g., increased body temperature and local inflammation of the udder) were present. Although they reported that cows tended to spend less time lying on the side of the affected quarter compared with baseline readings, the proportion of time spent lying on each side did not change after mastitis induction. Zimov et al. (2011) also found that cows infused with LPS spent less time lying down during the first 12 $\mathrm{h}$ after infusion compared with the period of 12 to $24 \mathrm{~h}$ after infusion, although it is not clear whether these differences were statistically significant or just numerical. In the current study, the decrease in lying behavior on the day of challenge was driven by the period of 4 to 7 $\mathrm{h}$ after LPS infusion. From previous published research, we expected that the most severe systemic signs would occur $4 \mathrm{~h}$ after LPS infusion (Banting et al., 2000; Zimov et al., 2011). The E. coli LPS challenge model of experimentally induced clinical mastitis used in this trial resulted in a short-duration episode, which would therefore only briefly affect lying activity. A naturally occurring E. coli infection of the mammary gland could result in more long-term and severe clinical signs of infection (Hogan and Smith, 2003), and therefore, longer and more noticeable changes in lying activity. More severe signs of inflammation, if unilateral, could also lead to changes in the proportion of time cows spend lying on each side. Further research is needed on a larger scale to investigate the use of changes in lying behavior for timely identification of cases of naturally occurring mastitis, and to monitor their recovery after treatment.

In conclusion, this preliminary study has shown that an episode of induced clinical mastitis can result in a reduction in the amount of time that cattle will designate to lying down. Given that lying is a high-priority behavior in dairy cows, and that increased lying time is an adaptive sickness behavior to facilitate recovery, we inferred that this reduction in lying time might present a concern for cows with clinical mastitis. Although additional studies with a larger number of animals are needed, automated monitoring of lying behavior could be an important component of future on-farm early detection of health problems, such as mastitis.

\section{ACKNOWLEDGMENTS}

The authors thank Jeff McFarlane and Laura Wright of the University of Guelph Ponsonby Dairy Research Centre for technical assistance, as well as for facilitating data collection. The study was funded by NSERC, Alberta Milk, Dairy Farmers of New Brunswick, Nova Scotia, Ontario and Prince Edward Island, Novalait Inc., Dairy Farmers of Canada, Canadian Dairy Network, AAFC, PHAC, Technology PEI Inc., Université de Montréal and University of Prince Edward Island through a grant from the Canadian Bovine Mastitis Research Network. Núria Chapinal was supported by a Beatriu de Pinós postdoctoral grant from the Generalitat de Catalunya.

\section{REFERENCES}

Arave, C. W., and J. L. Walters. 1980. Factors affecting lying behavior and stall utilization of dairy cattle. Appl. Anim. Ethol. 6:369-376.

Aubert, A. 1999. Sickness and behavior in animals: A motivational perspective. Neurosci. Biobehav. Rev. 23:1029-1036.

Banting, A., H. Schmidt, and S. Banting. 2000. Efficacy of meloxicam in lactating cows with $E$. coli endotoxin-induced acute mastitis. J. Vet. Pharmacol. Ther. 23:E4.

Canadian Council on Animal Care. 2009. Guidelines on: The Care and Use of Farm Animals in Research, Teaching and Testing. Canadian Council on Animal Care, Ottawa, ON, Canada.

Dantzer, R. 2001. Cytokine-induced sickness behavior: Where do we stand? Brain Behav. Immun. 15:7-24.

Forsberg, A. M., G. Pettersson, T. Ljungberg, and K. SvennerstenSjaunja. 2008. A brief note about cow lying behavior-Do cows choose left and right lying side equally? Appl. Anim. Behav. Sci. 114:32-36.

Fregonesi, J. A., and J. D. Leaver. 2001. Behavior, performance and health indicators of welfare for dairy cows housed in straw yard or cubicle systems. Livest. Prod. Sci. 68:205-216.

Grant, R. J., V. F. Colenbrander, and J. L. Albright. 1990. Effect of particle size of forage and rumen cannulation upon chewing activity and laterality in dairy cows. J. Dairy Sci. 73:3158-3164.

Haley, D. B., J. Rushen, and A. M. de Passillé. 2000. Behavioral indicators of cow comfort: Activity and resting behavior of dairy cows in two types of housing. Can. J. Anim. Sci. 80:257-263.

Hart, B. L. 1988. Biological basis of the behavior of sick animals. Neurosci. Biobehav. Rev. 12:123-137.

Hogan, J., and K. L. Smith. 2003. Coliform mastitis. Vet. Res. 34:507-519.

Ito, K., D. M. Weary, and M. A. G. von Keyserlingk. 2009. Lying behavior: Assessing within- and between-herd variation in freestallhoused dairy cows. J. Dairy Sci. 92:4412-4420.

Johnson, R. W. 2002. The concept of sickness behavior: A brief chronological account of four key discoveries. Vet. Immunol. Immunopathol. 87:443-450. 
Ladewig, J., and D. Smidt. 1989. Behavior, episodic secretion of cortisol and adrenocortical reactivity in bulls subjected to tethering. Horm. Behav. 23:344-360.

Ledgerwood, D. N., C. Winckler, and C. B. Tucker. 2010. Evaluation of data loggers, sampling intervals, and editing techniques for measuring the lying behavior of dairy cattle. J. Dairy Sci. 93:5129-5139.

Metz, J. H. M. 1985. The reaction of cows to a short-term deprivation of lying. Appl. Anim. Behav. Sci. 13:301-307.

Munksgaard, L., and H. B. Simonsen. 1996. Behavioral and pituitary adrenal axis response of dairy cows to social isolation and deprivation of lying down. J. Anim. Sci. 74:769-778.

Munksgaard, L., M. B. Jensen, L. J. Pedersen, S. W. Hansen, and L. Matthews. 2005. Quantifying behavioral priorities - Effects of time constraints on behavior of dairy cows, Bos taurus. Appl. Anim. Behav. Sci. 92:3-14.

Ruckebusch, Y. 1974. Sleep deprivation in cattle. Brain Res. 78:495499.

Siivonen, J., S. Taponen, M. Hovinen, M. Pastell, B. J. Lensink, S. Pyörälä, and L. Hänninen. 2011. Impact of acute clinical mastitis on cow behavior. Appl. Anim. Behav. Sci. 132:101-106.

Zimov, J. L., N. A. Botheras, W. P. Weiss, and J. S. Hogan. 2011. Associations among behavioral and acute physiologic responses to lipopolysaccharide induced clinical mastitis in lactating dairy cows. Am. J. Vet. Res. 72:620-627. 